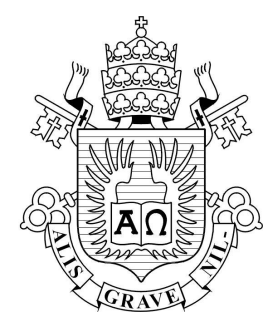

Suelen Rodrigues

\title{
Influência da Taxa de Carregamento sobre a Resistência de Aderência entre CFC e Concreto
}

\section{Dissertação de Mestrado}

Dissertação apresentada ao Programa de Pós-Graduação em Engenharia Civil da PUC-Rio como requisito parcial para obtenção do título de Mestre em Engenharia Civil.

Orientador: Giuseppe Barbosa Guimarães

Rio de Janeiro

Agosto de 2009. 


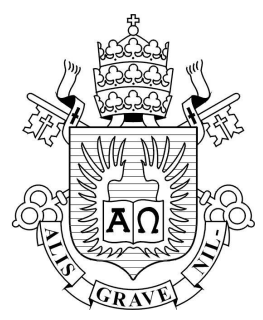

Suelen Rodrigues

\section{Influência da Taxa de Carregamento sobre a Resistência de Aderência entre CFC e Concreto}

Dissertação apresentada como requisito parcial para obtenção do título de Mestre pelo Programa de PósGraduação em Engenharia Civil da PUC-Rio. Aprovada pela Comissão Examinadora abaixo assinada.

Giuseppe Barbosa Guimarães Orientador Departamento de Engenharia Civil - PUC-Rio

Emil de Souza Sánchez Filho Programa de Pós-graduação em Engenharia Civil - UFF

Paulo Batista Gonçalves Departamento de Engenharia Civil - PUC-Rio Marta de Souza Lima Velasco Departamento de Engenharia Civil - PUC-Rio José Eugênio Leal Coordenador Setorial do Centro Técnico Científico - PUC-Rio

Rio de Janeiro, 28 de Agosto de 2009. 
Todos os direitos reservados. É proibida a reprodução total ou parcial do trabalho sem autorização da universidade, da autora e do orientador.

\section{Suelen Rodrigues}

Graduada em Engenharia Civil pela Universidade Estadual do Oeste do Paraná em março de 2007.

Ficha Catalográfica

Rodrigues, Suelen

Influência da Taxa de Carregamento sobre a Resistência de Aderência entre CFC e Concreto / Suelen Rodrigues; orientador: Giuseppe Barbosa Guimarães 2009.

122 f.; il. (color.) $30 \mathrm{~cm}$

Dissertação (Mestrado em Engenharia Civil) Pontifícia Universidade Católica do Rio de Janeiro, Rio de Janeiro, 2009.

Inclui bibliografia

1. Engenharia civil - Teses. 2. Reforço estrutural. 3. Fibras de carbono. 4. Carga de impacto. 5. Aderência. I. Guimarães, Giuseppe Barbosa. II. Pontifícia Universidade Católica do Rio de Janeiro. Departamento de Engenharia Civil. III. Título.

CDD: 624 


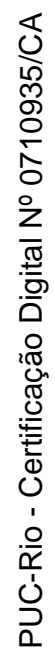

A minha querida Mãe, pelo amor, incentivo, apoio e confiança. 


\section{Agradecimentos}

Desejo expressar o meu reconhecimento a todas as pessoas e entidades que contribuíram, direta e indiretamente, para a realização e conclusão deste trabalho.

A minha Família, que nunca mediu esforços para tornar possível a concretização dos meus sonhos, dando apoio, carinho e incentivo durante toda minha vida.

Ao meu amor Felipe, obrigada pelo apoio e compreensão nos finais de semana dedicados a este trabalho.

Ao meu orientador, professor Giuseppe Barbosa Guimarães, pela oportunidade, incentivo, pelos ensinamentos prestados e pela orientação recebida ao longo da realização deste trabalho.

Aos meus amigos de Cascavel-PR, que mesmo distantes sempre torceram pelas minhas conquistas e me incentivaram nos momentos de desânimo.

Aos amigos Maria Bernadete, Algemiro Augusto, Arthur, Luciana e Vinicius, pela convivência, apoio e amizade sincera.

Aos amigos conquistados durante esse período na PUC, Juliana, Larissa, Magnus, João, Patrícia, Camilo, Flavia, Danilo, Vagner e Thais por terem sido grandes companheiros durante esta jornada.

Ao amigo Antonio, pela ajuda e apoio constante que foram essenciais no desenvolvimento deste trabalho.

Aos funcionários do Laboratório de Estruturas Euclídes, José Nilson, Evandro e Haroldo pela colaboração em todas as etapas do programa experimental.

Ao Emerson e a Anne, por me acolherem como filha, obrigada pelos passeios e encontros de família.

Ao Engenheiro Paulo de Tarso e À SIKA pelo fornecimento do tecido de fibra de carbono e da resina utilizados neste trabalho.

Ao CNPq pelo auxílio financeiro à pesquisa.

Ao IBQN, em especial a Annelise, pela compreensão na finalização desta dissertação.

E, finalmente, a Deus por ter me abençoado muito durante toda a vida e por ser sempre o guia das minhas decisões. 


\section{Resumo}

Rodrigues, Suelen; Guimarães, Giuseppe Barbosa. Influência da Taxa de Carregamento sobre a Resistência de Aderência entre CFC e Concreto. Rio de Janeiro, 2009. 122p. Dissertação de Mestrado - Departamento de Engenharia Civil, Pontifícia Universidade Católica do Rio de Janeiro.

Neste trabalho é realizada uma investigação experimental sobre os efeitos de cargas de impacto sobre a resistência de aderência entre o compósito de fibras de carbono e o concreto. O objetivo foi verificar a influência da taxa de carregamento sobre a resistência de aderência. O programa experimental consistiu em ensaios de quarenta e cinco corpos-de-prova, constituídos de blocos de concreto e tiras de fibras de carbono coladas nas laterais opostas dos blocos. As variáveis de estudo foram a resistência à compressão do concreto $(25 \mathrm{MPa}, 45 \mathrm{MPa}$ e $65 \mathrm{MPa})$ e a taxa de carregamento que variou de um mínimo de 1,92 MPa/s (estático) para um máximo de $438685 \mathrm{MPa} / \mathrm{s}$ (dinâmico). Os resultados dos ensaios mostraram que a resistência de aderência foi afetada pela taxa de carregamento.

\section{Palavras Chave}

Reforço Estrutural; Impacto; Concreto; Compósitos de Fibras de Carbono; Aderência. 


\section{Abstract}

Rodrigues, Suelen; Guimarães, Giuseppe Barbosa (Advisor). Influence of Loading Rate on the Bond Strength between CFC and Concrete. Rio de Janeiro, 2009. 122p. MSc Dissertation -Departamento de Engenharia Civil, Pontifícia Universidade Católica do Rio de Janeiro.

An experimental investigation on the effects of impact loading on the bond strength between carbon fiber composite and concrete is described in this work. The objective was to verify the influence of loading rate on the bond strength. The experimental program consisted on testing of forty five specimens made of concrete blocks and carbon fiber strips glued on opposite sides of the block. The variables studied were the concrete compressive strength (25 MPa, $45 \mathrm{MPa}$ and 65 $\mathrm{MPa}$ ) and loading rate which varied from a minimum of $1,92 \mathrm{MPa} / \mathrm{s}$ (static) to a maximum of $438685 \mathrm{MPa} / \mathrm{s}$ (dynamic). Test results showed that the bond strength was affected by loading rate.

\section{Keywords} Bond.

Structural Strengthening; Concrete; Carbon Fiber Composites; Impact Load; 


\section{Sumário}

1. Introdução 21

1.1. Considerações Iniciais $\quad 21$

$\begin{array}{ll}\text { 1.2. Objetivos } & 21\end{array}$

1.3. Organização do Trabalho 22

2. Revisão Bibliográfica 23

2.1. Considerações Iniciais 23

2.2. Materiais Compósitos 23

2.2.1. Fibras 23

2.2.2. Matriz 25

2.3. Compósitos de Fibras de Carbono 27

2.4. Aderência entre o CFC e o Substrato de Concreto 27

2.4.1. CHEN e TENG (2001) 28

2.4.2. NAKABA et al. (2001) 30

2.4.3. MENEGHEL (2005) 32

2.4.4. PACHECO (2006) 33

2.4.5. BARROS et al. (2007) 35

2.5. Estudos sobre cargas de impacto relacionados aos materiais compósitos $\quad 37$

2.5.1. ERKI e MEIER (1999) 37

2.5.2. WHITE et al. (2001) 39

2.5.3. TANG e SAADATMANESH (2003) 41

2.5.4. PELLISSARI (2007) 43

3. Programa Experimental 46

3.1. Considerações Iniciais 46

3.2. Características dos Corpos-de-prova 46

3.3. Nomenclatura $\quad 47$

3.4. Materiais 49

3.4.1. Concreto 49 
3.4.2. Tecido de Fibras de Carbono

3.4.3. Adesivo Epóxi 52

3.5. Ensaio de resistência à tração do compósito de fibra de carbono 53

3.6. Aplicação do Compósito de Fibras de Carbono 56

3.7. Instrumentação 60

3.8. Aquisição de Dados 61

3.9. Descrição dos Ensaios 61

3.9.1. Carregamento Dinâmico 61

3.9.2. Carregamento Estático 63

4. Apresentação e Análise dos Resultados 65

4.1. Considerações Iniciais 65

4.2. Interpretação dos resultados $\quad 65$

4.3. Modos de Ruptura $\quad 77$

4.4. Força de Ruptura e Resistência de Aderência 78

4.5. Influência da Taxa de Carregamento sobre a Resistência de Aderência

5. Conclusões e Sugestões para Trabalhos Futuros 85

5.1. Conclusões 85

5.2. Sugestões para Trabalhos Futuros 85

6. Referências Bibliográficas 87

$\begin{array}{ll}\text { Anexo A - Caracterização dos Agregados } & 91\end{array}$

Anexo B - Determinação das Massas Específicas dos Agregados Graúdo e Miúdo

Anexo C - Gráficos dos Resultados dos Ensaios 96

$\begin{array}{ll}\text { Anexo D - Fotos dos corpos-de-prova } & 115\end{array}$ 


\section{Lista de Figuras}

Figura 2.1 - Diagrama tensão-deformação específica de fibras e metais, adaptada de BEBER (2003).

Figura 2.2 - a) Cisalhamento simples; b) Cisalhamento duplo; c) Vista superior; adaptada de CHEN e TENG (2001). 28

Figura 2.3 - Corpos-de-prova para o ensaio de aderência; adaptada de NAKABA et al. (2001). 30

Figura 2.4 - Tensão de aderência vs. deslocamento; adaptada de NAKABA et al. (2001).

Figura 2.5 - Esquema simplificado do ensaio de tração-compressão; adaptada de MENEGHEL (2005).

Figura 2.6 - Deformação específica x distância ao longo do comprimento de ancoragem; adaptada de MENEGHEL (2005).

Figura 2.7 - Resistência de aderência $\left(f_{\mathrm{b}}\right)$ vs. tipo de superfície do concreto; adaptada de PACHECO (2006).

Figura 2.8 - Geometria dos modelos e configurações dos ensaios; adaptada de BARROS et al. (2007).

Figura 2.9 - a) Influência do comprimento de aderência $\left(L_{a}\right)$ na relação força de arrancamento vs deslizamento; b) Influência do comprimento de aderência $\left(L_{a}\right)$ na relação tensão media de corte vs deslizamento; adaptada de BARROS et al. (2007).

Figura 2.10 - Configuração das vigas; adaptada de ERKI e MEIER (1999). 38

Figura 2.11 - Características das vigas; adaptada de WHITE et al.(2001). 39

Figura 2.12 - Gráfico tri linear de carregamento vs. flexão; adaptada de HEFFERNAN (1997) apud.WHITE et al. (2001).

Figura 2.13 - Esquema de ensaio; adaptada de TANG e SAADATMANESH (2005).

Figura 2.14 - Gráfico força de reação máxima vs. altura de queda do martelo; adaptada de TANG e SAADATMANESH (2003).

Figura 2.15 - Características geométricas dos corpos-de-prova estudados por PELLISSARI (2007).

Figura 2.16 - Aparato de ensaio usado por PELLISSARI (2007). 
Figura 2.17 - Relação entre a taxa de tensão de aderência $\left(T_{\tau}\right)$ e a resistência de aderência $\left(f_{b}\right)$ para os corpos-de-prova que romperam por destacamento do concreto, adaptada de PELLISSARI (2007). 45

Figura 3.1 - Detalhe do corpo de prova (medidas em mm). 46

Figura 3.2 - Detalhes da forma metálica. 47

Figura 3.3 - Detalhe da concretagem dos blocos e dos corpos-de-prova. $\quad 50$

Figura 3.4 - Tecido de fibra de carbono Sika Wrap - 330 C. 52

Figura 3.5 - Adesivo de epóxi Sikadur - 330. 53

Figura 3.6 - Dimensões dos corpos-de-prova para ensaio de tração (ASTM D 3039/3039M). 54

Figura 3.7 - Ensaio de corpo-de-prova CFC. 54

Figura 3.8 - Diagrama tensão-deformação específica dos corpos-de-prova de CFC. $\quad 56$

Figura 3.9 - Detalhe da corte do tecido de fibras de carbono. 56

Figura 3.10 - Detalhe das tiras de fibras de carbono com adesivo epóxi. $\quad 57$

Figura 3.11 - Detalhe da preparação da região a receber o CFC. 58

Figura 3.12 - Detalhamento da região destinada ao recebimento do CFC. $\quad 58$

Figura 3.13 - Blocos com compósito de fibras de carbono. 59

Figura 3.14 - Detalhe do bloco com CFC. 59

Figura 3.15 - Posicionamento da célula de carga. 60

Figura 3.16 - Detalhe do extensômetro colado no CFC. 60

Figura 3.17 - Detalhe do equipamento de ensaio - vista lateral. 62

Figura 3.18 - Detalhe do aparato para aplicação de carga - vista frontal. 63

Figura 3.19 - Posicionamento do atuador hidráulico para a realização dos ensaios estáticos. $\quad 64$

Figura 4.1 - Representação esquemática do sistema analisado. 66

Figura 4.2 - Curva força aplicada vs. tempo para o corpo-de-prova B45-0-01. 68

Figura 4.3 - Curva deformação específica nas tiras de fibras de carbono vs. tempo para o corpo-de-prova B45-0-01. 68

Figura 4.4 - Curva força aplicada vs. tempo para o corpo-de-prova B65-0-01. 69 Figura 4.5 - Curva deformação específica nas tiras de fibras de carbono vs. tempo para o corpo-de-prova B65-0-01. 69

Figura 4.6 - Curva força vs. tempo para o corpo-de-prova B25-25-E. $\quad 70$ 
Figura 4.7 - Curva deformação específica nas tiras de carbono vs. tempo para o $\begin{array}{ll}\text { corpo-de-prova B25-25-E. } & 70\end{array}$

Figura 4.8 - Curva força vs. tempo para o corpo-de-prova B25-75-E. 71

Figura 4.9 - Curva deformação específica nas tiras de carbono vs. tempo para o corpo-de-prova B25-75-E. 71

Figura 4.10 - Curva força vs. tempo do corpo-de-prova B25-125-E. 72

Figura 4.11 - Curva deformação específica nas tiras de carbono vs. tempo para o corpo-de-prova B25-125-E.

Figura 4.12 - Forças de inércia $\left(F_{i}\right)$, elástica $\left(F_{e}\right)$ e impulso $(P)$ no corpo-de-prova B25-25-E.

Figura 4.13 - Forças de inércia $\left(F_{i}\right)$, elástica $\left(F_{e}\right)$ e impulso $(P)$ no corpo-de-prova B25-75-E.

Figura 4.14 - Forças de inércia $\left(F_{i}\right)$, elástica $\left(F_{e}\right)$ e impulso $(P)$ no corpo-de-prova B25-125-E.

Figura 4.15 - Modos de ruptura: (a) destacamento do concreto (ruptura da aderência); (b) ruptura por tração nas fibras.

Figura 4.16 - Identificação do valor máximo da força elástica $\left(F_{e, M a x}\right)$ e do tempo $\left(\Delta \mathrm{t}_{\mathrm{e}}\right)$ no corpo-de-prova B25-75-E.

Figura 4.17- Resistência de aderência $\left(f_{b}\right)$ vs. taxa de carregamento $\left(T_{c}\right)$ para corpos-de-prova com resistência a compressão de $25 \mathrm{MPa}$.

Figura 4.18 - Resistência de aderência $\left(f_{b}\right)$ vs. taxa de carregamento $\left(T_{c}\right)$ para corpos-de-prova com resistência a compressão de $45 \mathrm{MPa}$.

Figura 4.19 - Resistência de aderência $\left(f_{b}\right)$ vs. taxa de carregamento $\left(T_{c}\right)$ para corpos-de-prova com resistência a compressão de $65 \mathrm{MPa}$.

Figura 4.20 - Resistência de aderência vs. taxa de carregamento.

Figura C.1 - Curva força vs. tempo para o corpo-de-prova B25-0-01.

Figura C.2 - Curva deformação específica vs. tempo para o corpo-de-prova B25-0-01.

Figura C.3 - Curva força vs. tempo para o corpo-de-prova B25-0-02.

Figura C.4 - Curva deformação específica vs. tempo para o corpo-de-prova B25-0-02.

Figura C.5 - Curva força vs. tempo para o corpo-de-prova B45-0-01.

Figura C.6 - Curva deformação específica vs. tempo para o corpo-de-prova B45-0-01. 
Figura C.7 - Curva força vs. tempo para o corpo-de-prova B45-0-02.

Figura C.8 - Curva deformação específica vs. tempo para o corpo-de-prova

B45-0-02.

Figura C.9 - Curva força vs. tempo para o corpo-de-prova B65-0-01.

Figura C.10 - Curva deformação específica vs. tempo para o corpo-de-prova B65-0-01.

Figura C.11 - Curva força vs. tempo para o corpo-de-prova B65-0-02.

Figura C.12 - Curva deformação específica vs. tempo para o corpo-de-prova B65-0-02.

Figura C.13 - Curva deformação específica vs. tempo para o corpo-de-prova B25-25-E.

Figura C.14 - Forças de inércia $(F i)$, elástica $(F e)$ e impulso $(P)$ no corpo-deprova $\mathrm{B} 25-25-\mathrm{E}$

101

Figura C.15 - Forças de inércia $(F i)$, elástica $(F e)$ e impulso $(P)$ no corpo-deprova B25-25-01.

Figura C.16 - Forças de inércia $(F i)$, elástica $(F e)$ e impulso $(P)$ no corpo-deprova B25-25-02.

Figura C.17 - Forças de inércia $(F i)$, elástica $(F e)$ e impulso $(P)$ no corpo-deprova B25-50-01.

102

Figura C.18 - Forças de inércia $(F i)$, elástica $(F e)$ e impulso $(P)$ no corpo-deprova B25-50-02.

102

Figura C.19 - Curva deformação específica vs. tempo para o corpo-de-prova B25-75-E.

Figura C.20 - Forças de inércia $(F i)$, elástica $(F e)$ e impulso $(P)$ no corpo-deprova B25-75-E.

Figura C.21 - Forças de inércia $(F i)$, elástica $(F e)$ e impulso $(P)$ no corpo-deprova B25-75-01.

Figura C.22 - Forças de inércia $(F i)$, elástica $(F e)$ e impulso $(P)$ no corpo-deprova B25-75-02.

Figura C.23 - Forças de inércia $(F i)$, elástica $(F e)$ e impulso $(P)$ no corpo-deprova B25-100-01.

Figura C.24 - Forças de inércia $(F i)$, elástica $(F e)$ e impulso $(P)$ no corpo-deprova $\mathrm{B} 25-100-02$. 
Figura C.25 - Curva deformação específica vs. tempo para o corpo-de-prova B25-125-E.

Figura C.26 - Forças de inércia $(F i)$, elástica $(F e)$ e impulso $(P)$ no corpo-deprova B25-125-E.

Figura C.27 - Forças de inércia $(F i)$, elástica $(F e)$ e impulso $(P)$ no corpo-deprova B25-125-01.

Figura C.28 - Forças de inércia $(F i)$, elástica $(F e)$ e impulso $(P)$ no corpo-deprova B25-125-02.

Figura C.29 - Forças de inércia $(F i)$, elástica $(F e)$ e impulso $(P)$ no corpo-deprova B25-150-01.

Figura C.30 - Forças de inércia $(F i)$, elástica $(F e)$ e impulso $(P)$ no corpo-deprova $\mathrm{B} 25-150-02$.

Figura C.31 - Forças de inércia $(F i)$, elástica $(F e)$ e impulso $(P)$ no corpo-deprova B45-25-01.

Figura C.32 - Forças de inércia $(F i)$, elástica $(F e)$ e impulso $(P)$ no corpo-deprova B45-25-02.

Figura C.33 - Forças de inércia $(F i)$, elástica $(F e)$ e impulso $(P)$ no corpo-deprova B45-50-01.

Figura C.34 - Forças de inércia $(F i)$, elástica $(F e)$ e impulso $(P)$ no corpo-deprova B45-50-02.

Figura C.35 - Forças de inércia $(F i)$, elástica $(F e)$ e impulso $(P)$ no corpo-deprova B45-75-01.

Figura C.36 - Forças de inércia $(F i)$, elástica $(F e)$ e impulso $(P)$ no corpo-deprova B45-75-02.

Figura C.37 - Forças de inércia $(F i)$, elástica $(F e)$ e impulso $(P)$ no corpo-deprova B45-100-01.

Figura C.38 - Forças de inércia $(F i)$, elástica $(F e)$ e impulso $(P)$ no corpo-deprova B45-100-02.

Figura C.39 - Forças de inércia $(F i)$, elástica $(F e)$ e impulso $(P)$ no corpo-deprova B45-125-01.

Figura C.40 - Forças de inércia $(F i)$, elástica $(F e)$ e impulso $(P)$ no corpo-deprova B45-125-02.

Figura C.41 - Forças de inércia $(F i)$, elástica $(F e)$ e impulso $(P)$ no corpo-deprova B45-150-01. 
Figura C.42 - Forças de inércia $(F i)$, elástica $(F e)$ e impulso $(P)$ no corpo-deprova B45-150-02.

Figura C.43 - Forças de inércia $(F i)$, elástica $(F e)$ e impulso $(P)$ no corpo-deprova B65-25-01.

Figura C.44 - Forças de inércia $(F i)$, elástica $(F e)$ e impulso $(P)$ no corpo-deprova B65-25-02.

Figura C.45 - Forças de inércia $(F i)$, elástica $(F e)$ e impulso $(P)$ no corpo-deprova B65-50-01.

Figura C.46 - Forças de inércia $(F i)$, elástica $(F e)$ e impulso $(P)$ no corpo-deprova B65-50-02.

Figura C.47 - Forças de inércia $(F i)$, elástica $(F e)$ e impulso $(P)$ no corpo-deprova B65-75-01.

Figura C.48 - Forças de inércia $(F i)$, elástica $(F e)$ e impulso $(P)$ no corpo-deprova $\mathrm{B} 65-75-02$.

Figura C.49 - Forças de inércia $(F i)$, elástica $(F e)$ e impulso $(P)$ no corpo-deprova B65-100-01.

Figura C.50 - Forças de inércia $(F i)$, elástica $(F e)$ e impulso $(P)$ no corpo-deprova B65-100-02.

Figura C.51 - Forças de inércia $(F i)$, elástica $(F e)$ e impulso $(P)$ no corpo-deprova B65-125-01.

Figura C.52 - Forças de inércia $(F i)$, elástica $(F e)$ e impulso $(P)$ no corpo-deprova B65-125-02.

Figura C.53 - Forças de inércia $(F i)$, elástica $(F e)$ e impulso $(P)$ no corpo-deprova B65-150-01.

Figura C.54 - Forças de inércia $(F i)$, elástica $(F e)$ e impulso $(P)$ no corpo-deprova B65-150-02.

Figura D.01 - (a) corpo-de-prova B25-25-01 e (b) corpo-de-prova B25-25-02. 115

Figura D.02 - (a) corpo-de-prova B25-50-01 e (b) corpo-de-prova B25-50-02. 115

Figura D.03 - (a) corpo-de-prova B25-75-01 e (b) corpo-de-prova B25-75-02. 115

Figura D.04 - (a) corpo-de-prova B25-100-01 e (b) corpo-de-prova B25-100-02.

Figura D.05 - (a) corpo-de-prova B25-125-01 e (b) corpo-de-prova B25-125-02. 
Figura D.06 - (a) corpo-de-prova B25-150-01 e (b) corpo-de-prova B25-150-02.

Figura D.07 - (a) corpo-de-prova B45-25-01 e (b) corpo-de-prova B45-25-02. 117 Figura D.08 - (a) corpo-de-prova B45-50-01 e (b) corpo-de-prova B45-50-02. 117 Figura D.09 - (a) corpo-de-prova B45-75-01 e (b) corpo-de-prova B45-75-02. 117 Figura D.10 - (a) corpo-de-prova B45-100-01 e (b) corpo-de-prova B45-100-02.

Figura D.11 - (a) corpo-de-prova B45-125-01 e (b) corpo-de-prova B45-125-02.

Figura D.12 - (a) corpo-de-prova B45-150-01 e (b) corpo-de-prova B45-150-02.

Figura D.13 - (a) corpo-de-prova B65-25-01 e (b) corpo-de-prova B65-25-02. 119 Figura D.14 - (a) corpo-de-prova B65-50-01 e (b) corpo-de-prova B65-50-02. 119 Figura D.15 - (a) corpo-de-prova B65-75-01 e (b) corpo-de-prova B65-75-02. 119 Figura D.16 - (a) corpo-de-prova B65-100-01 e (b) corpo-de-prova B65-100-02.

Figura D.17 - (a) corpo-de-prova B65-125-01 e (b) corpo-de-prova B65-125-02.

Figura D.18 - (a) corpo-de-prova B65-150-01 e (b) corpo-de-prova B65-150-02.

Figura D.19 - (a) corpo-de-prova B25-25-E, (b) corpo-de-prova B25-750-E e (c) corpo-de-prova B25-125-E.

Figura D.20 - (a) corpo-de-prova B25-0-01 (b) corpo-de-prova B25-0-02. 121

Figura D.21 - (a) corpo-de-prova B45-0-01 (b) corpo-de-prova B45-0-02. 122

Figura D.22 - (a) corpo-de-prova B65-0-01 (b) corpo-de-prova B65-0-02. 122 


\section{Lista de Tabelas}

Tabela 2.1 - Propriedades típicas de algumas fibras (KENDALL, 1999).

Tabela 2.2 - Propriedades das resinas utilizadas em materiais compósitos

(CAROLIN, 2003). 26

Tabela 2.3 - Valores das principais grandezas; adaptada de BARROS et al. (2007).

Tabela 2.4 - Carregamento das vigas ensaiadas; adaptada de WHITE et al. (2001).

Tabela 3.1 - Nomenclatura dos corpos-de-prova. $\quad 48$

Tabela 3.2 - Nomenclatura dos corpos-de-prova com extensômetros. 48

Tabela 3.3 - Consumo de material por $\mathrm{m}^{3}$ de concreto. 49

Tabela 3.4 - Resultado dos ensaios de resistência à compressão do concreto 51

Tabela 3.5 - Dimensões dos corpos-de-prova para o ensaio de tração em materiais compósitos de fibras de carbono (ASTM D 3039/3039M). 53

Tabela 3.6 - Resultados obtidos nos ensaios à tração dos corpos-de-prova de compósitos de fibras de carbono. $\quad 55$

Tabela 4.1 - Cálculo das forças de inércia e elástica no corpo-de-prova B25-25-E.

Tabela 4.2 - Resultados experimentais dos corpos-de-prova da série $f_{c, n}=25 \mathrm{MPa}$.

Tabela 4.3 - Resultados experimentais dos corpos-de-prova da série $f_{c, n}=45 \mathrm{MPa}$.

Tabela 4.4 - Resultados experimentais dos corpos-de-prova da série $f_{c, n}=65 \mathrm{MPa}$.

Tabela A.1 - Resultado da análise granulométrica do agregado miúdo. $\quad 91$

Tabela A.2 - Resultado da análise granulométrica do agregado graúdo. 92 


\section{Lista de Símbolos}

Romanos

\begin{tabular}{|c|c|}
\hline$A$ & Área da seção transversal do corpo-de-prova \\
\hline$A_{c}$ & Área da seção transversal do concreto \\
\hline$A_{f}$ & Área da seção transversal do CFC \\
\hline$b_{c}$ & Largura do elemento de concreto \\
\hline$b_{f}$ & Largura do compósito de fibra de carbono \\
\hline$b_{p}$ & Largura do reforço de CFC \\
\hline$C F C$ & Compósito de fibras de carbono \\
\hline$D_{\max }$ & Dimensão máxima característica do agregado \\
\hline$E_{c}$ & Módulo de elasticidade do concreto \\
\hline$E_{f}$ & Módulo de elasticidade do CFC \\
\hline$F_{e}$ & Força elástica \\
\hline$F_{e, \max }$ & Força elástica máxima \\
\hline$F_{i}$ & Força de inércia \\
\hline$F_{\max }$ & Força máxima aplicada no CFC \\
\hline$F_{u}$ & Força última \\
\hline$f_{c}$ & Resistência à compressão do concreto \\
\hline$f_{b}$ & Resistência de aderência \\
\hline$f_{c, n}$ & Resistência nominal do concreto \\
\hline$f_{c, \text { dosag }}$ & Resistência de dosagem do concreto \\
\hline$f_{t f}$ & Resistência à tração \\
\hline rica & Energia de fratura segundo o modelo de Holz \\
\hline
\end{tabular}




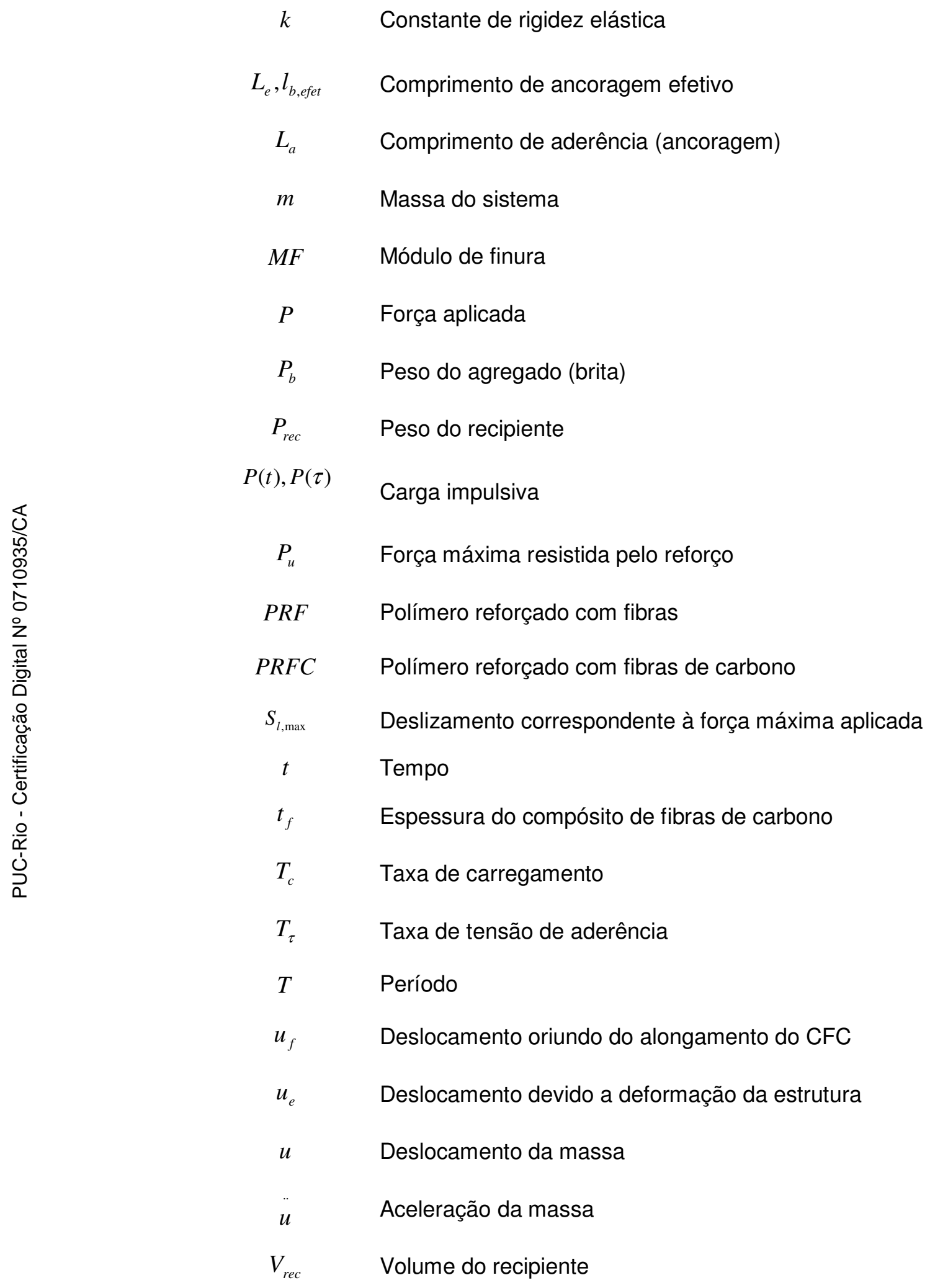




\begin{tabular}{|c|c|}
\hline Gregos & \\
\hline$\beta_{p}$ & $\begin{array}{l}\text { Coeficiente adimensional que relaciona a largura do } \\
\text { compósito com a largura do elemento de concreto }\end{array}$ \\
\hline$\Delta t_{e}$ & Tempo de carregamento \\
\hline$\Delta l_{b}$ & Distância entre os extensômetros \\
\hline $\mathcal{E}_{f, \max }$ & Deformação específica máxima registrada no extensômetro \\
\hline$\varepsilon_{f, u}$ & Deformação específica última \\
\hline $\mathcal{E}_{f, i}, \mathcal{E}_{f}$ & Deformação específica no tecido de PRF \\
\hline$\phi$ & Diâmetro \\
\hline$\gamma$ & Massa específica do agregado \\
\hline$\gamma_{b}$ & Massa específica aparente do agregado graúdo \\
\hline$\sigma$ & Tensão \\
\hline$\sigma_{d b}$ & Tensão de aderência no reforço \\
\hline$\sigma_{f}$ & Tensão normal no CFC \\
\hline$\tau_{b k}$ & Tensão de aderência característica \\
\hline$\tau_{\operatorname{máx}}$ & Tensão máxima de corte \\
\hline
\end{tabular}

